\title{
Article \\ Characterization of Failure Strain In Fiber Reinforced Composites: Under On-Axis and Off-Axis Loading
}

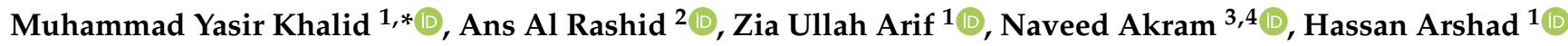 \\ and Fausto Pedro García Márquez ${ }^{5, * \mathbb{D}}$
}

1 Department of Mechanical Engineering, University of Management \& Technology (UMT) Lahore, Sialkot Campus, Lahore 51040, Pakistan; zia.arif@skt.umt.edu.pk (Z.U.A.); hassan.arshad@skt.umt.edu.pk (H.A.)

2 Division of Sustainable Development, College of Science and Engineering, Hamad Bin Khalifa University, Qatar Foundation, Doha 5825, Qatar; anrashid@hbku.edu.qa

3 Department of Mechanical Engineering, Mirpur University of Science and Technology (MUST), New Mirpur City, Azad Jammu and Kashmir 10250, Pakistan; naveed.me@must.edu.pk

4 Department of Mechanical Engineering, Faculty of Mechanical Engineering, University of Malaya, Kuala Lumpur 50603, Malaysia

5 Ingenium Research Group, University of Castilla-La Mancha, 13071 Ciudad Real, Spain

* Correspondence: yasirkhalid94@gmail.com (M.Y.K.); faustopedro.garcia@uclm.es (F.P.G.M.); Tel.: +34-926-95300 (F.P.G.M.)

\section{check for}

updates

Citation: Khalid, M.Y.; Rashid, A.A.; Arif, Z.U.; Akram, N.; Arshad, H.; García Márquez, F.P. Characterization of Failure Strain In Fiber Reinforced Composites: Under On-Axis and Off-Axis Loading. Crystals 2021, 11, 216. https://doi.org/10.3390/ cryst11020216

Academic Editors:

Heinz-Günter Brokmeier and Chan-Jung Kim

Received: 26 January 2021

Accepted: 14 February 2021

Published: 22 February 2021

Publisher's Note: MDPI stays neutral with regard to jurisdictional claims in published maps and institutional affiliations.

Copyright: (c) 2021 by the authors. Licensee MDPI, Basel, Switzerland. This article is an open access article distributed under the terms and conditions of the Creative Commons Attribution (CC BY) license (https:// creativecommons.org/licenses/by/ $4.0 /)$.

\begin{abstract}
Metals are known for high ductility and have, been used to design and fabricate structural components for many years. However, composite materials are taking over traditional materials owing to their significant mechanical properties. Fiber-reinforced composites exhibit lower ductility and failure strain, resulting in brittle failure, limiting their application where high ductility is desired. In this study, an effort has been made to design, fabricate, and test continuous fiber-reinforced composites with improved ductility. A comparative analysis was performed for optimizing the failure strain of different woven fiber-reinforced composite materials under both on-axis $\left(0^{\circ} / 90^{\circ}\right)$ and off-axis $\left( \pm 45^{\circ}\right)$ loading. The materials include carbon/epoxy, E-glass/epoxy, and jute/epoxy composite. The tests were performed according to ASTM D3039 standard. The strength of all tested composites in on-axis and off-axis loading was obtained from tensile test results. But failure strain was limited in on-axis loading. Interestingly, glass/epoxy composite showed improved failure strain, by $90 \%$, without much loss in tensile strength in off-axis loading than on-axis loading. The jute fiber revealed limited tensile strength and failure strain in both loading conditions.
\end{abstract}

Keywords: GFRP; CFRP; Jute; Composite; off-axis loading; Tensile test

\section{Introduction}

Composite materials have been under investigation since the seventies, especially where a high strength-to-weight ratio is a vital design variable. Fiber-reinforced composites are remarkably lightweight, possess excellent strength, and are the favored lightweight materials for several industries [1,2] including automobile [3,4] and railroad industries [5]. They can be found in many aircraft structures, such as the Boeing 737, Airbus 325, and F-35 [6]. Because of composite materials' anisotropic nature, their effectiveness depends on careful design and tailored properties for a particular application [7]. Materials in structural applications are often exposed to time-dependent and multi-axial loading conditions in many load-bearing applications [8]. Therefore, understanding the mechanical behavior of materials/structures at high strain rates and these loading conditions is essential $[6,9,10]$.

Due to the brittle nature of synthetic fibers, such as glass and carbon, the strain-tofailure of structural fiber-reinforced composites is known to be very low. Many researchers attempted to improve composite materials' ductility by including bendable/ductile steel strands and wires into these materials $[11,12]$. Others searched for in-plane shear $\pm 45^{\circ}$ under tensile test through standards such as tensile Hopkinson bar setup [13] and following 
other ASTM standards [10]. The ductility effect of composites and overall toughness, which can be related to particular applications, such as energy-absorbing structures, can be enhanced by choosing fibers with a higher strain-to-failure ratio (such as natural fibers; silk, and coconut) [14]. Many studies reported the response of the on-axis tensile failure of glass fibers [15] and carbon fibers [16-18] Yong Cao et al. [19] investigated experimentally and numerically tensile and compressive failure of angled ply consisting of woven carbon fabric reinforced composites. The authors found that the angle-ply layer had higher crack propagation resistance than $0^{\circ} / 90^{\circ}$ layers. M.G. Callens et al. [11] performed a study on the woven steel fiber-reinforced composites to investigate the effect of higher strain on failure. The testing under quasi-static conditions for these composites was performed as per ASTM D3039 standard. The results revealed that the proposed composites had four times more strain rate to failure ratio than traditional fiber-reinforced composites. A similar study on carbon reinforced composites presented the off-axis laminate layers' effect on the tensile response and was investigated through the ASTM D3039 standard. Results revealed that the effect of off-axis loading led to the short delamination length of the composite laminate [20].

Tim Bergmann et al. [21] conducted a $\pm 45^{\circ}$ off-axis tension test on different synthetic fiber-reinforced composites. It was found that the values of axial failure were in the $20-25 \%$ range when these composites were tested under off-axis loading, which is considered high when they were tested in the axial direction. In another study, a higher strain rate on woven glass/epoxy reinforced composite was imposed. The testing was performed on $\pm 45^{\circ}$ off-axis specimens. The results revealed that the composite's strength was higher for higher strain loading than quasi-strain loading in the off-axis mode [10]. Aruchamy et al. [22] elaborated on the effect of different fiber loading on hybrid cotton/bamboo hybrid composites' mechanical properties. It was concluded that the development of the weave pattern of cotton/bamboo improved the mechanical properties. Rabiee and Ghasemnejad [23] presented experimental and numerical approaches on the parameters affecting energy absorption of composite cylindrical structures at oblique loading through various inclined angles $\left(5^{\circ}, 10^{\circ}, 20^{\circ}\right.$, and $\left.30^{\circ}\right)$. The results showed that the energy absorption of these composites was decreased with the increasing incline angles. Yan et al. [16] studied the behavior of tensile fatigue of carbon-fiber-reinforced (unidirectional) under $45^{\circ}$ off-axis loading. Observation from the fracture surface of laminates exposed that their interfacial bonding capability was very low for high fatigue off-axis loading.

Natural fibers have gained a lot of interest in the development of bio-based polymer composites. Mostly plant fibers, such as flax, hemp, banana, and jute, are seen as biodegradable substitutes to conventional composite reinforcements [24-26]. The previous studies revealed that the Jute fiber provides improved mechanical properties in hybridization with synthetic fibers. Jute has a reasonable strain rate compared to other fibers in on-axis loading, increasing off-axis loading [14].

In addition, several analytical models are reported in the literature to predict the mechanical behavior of laminated composites. However, rather than analytical modeling, which assumes straightforward fiber break arrangements, numerical simulation of fiberreinforced composites offers significantly more reliable results than analytical techniques. Many researchers have extensively used these simulation techniques under on-axis loading $[27,28]$ but very few studies attempted to perform simulations under off-axis loading conditions [29].

Thus, from the above literature, it is evident that recent research is oriented toward synthetic and natural fibers, both unidirectional and woven reinforced composite off-axis tensile testing $\pm 45^{\circ}$. However, there is still exists plenty of gaps in off-axis testing of natural fibers reinforced composites. In addition, there is an absence of a particular and consistent method for this material's tension test. This study aims to fill the gap in lacking knowledge of off-axis loading of natural fibers, such as jute. In this study, both on-axis and off-axis loading on woven jute, carbon, and glass fibers are performed per ASTM D3039 standard. 
The samples are prepared through a hand layup technique. The results of natural fiber and synthetic fibers from on-axis and off-axis loading are finally compared.

\section{Materials and Methods}

This section presents the details on different materials and testing procedures adopted for this study. Table 1 reports the complete detail of materials, reinforcement and matrix/epoxy used in this study.

Table 1. Materials details.

\begin{tabular}{ccccccc}
\hline Fabric/Reinforcement & $\begin{array}{c}\text { Matrix } \\
\text { Type }\end{array}$ & $\begin{array}{c}\text { GSM } \\
\left(\mathbf{g} / \mathbf{m}^{\mathbf{2}}\right)\end{array}$ & $\begin{array}{c}\text { Woven } \\
\text { Type }\end{array}$ & $\begin{array}{c}\text { Thickness of } \\
\text { Fabric }(\mathbf{m m})\end{array}$ & \multicolumn{2}{c}{ Thread Count per 100 mm } \\
\cline { 6 - 8 } & & 170 & & 0.3 & Warp & 60 \\
E-Glass & EPOTEC YD & 195 & Plain & 0.35 & 48 & 65 \\
Carbon (3K) & 128 & 235 & & 0.75 & 30 & 37 \\
Jute & & & & & \\
\hline
\end{tabular}

\subsection{Samples Preparations}

Glass fabric, carbon fabric, and jute fabric reinforced epoxy composites were manufactured by the conventional hand layup technique [30]. The epoxy and hardener resin were mixed with an approximately 100:33 ratio for $10 \mathrm{~min}$. The entrapped air bubbles were removed carefully with a roller before the final curing at room temperature for $48 \mathrm{~h}$. Three types of samples were prepared for this study, as reported in Table 2. The manufactured samples were cut into three types for off-axis loading.

Table 2. Layup sequence details and designation.

\begin{tabular}{cc}
\hline Layup Sequence & Designation \\
\hline Glass layers $\times 5$ & $\mathrm{G} 5$ \\
Carbon layers $\times 5$ & $\mathrm{C} 5$ \\
Jute/Jute/Jute/Jute/Jute & $\mathrm{J} 5$ \\
Glass/Glass/Glass/Glass/Glass & $\mathrm{G} 5-450$ \\
Carbon/Carbon/Carbon/Carbon/Carbon & $\mathrm{C} 5-450$ \\
Jute/Jute/Jute/Jute/Jute & $\mathrm{J} 5-450$ \\
\hline
\end{tabular}

\subsection{Testing}

There are numerous standards for the tensile testing of composite materials. In this study, ASTM D3039 was selected due to simpler sample geometry. The tensile specimen testing details for both on-axis $\left(0^{\circ} / 90^{\circ}\right)$ and off-axis loading $\left(45^{\circ}\right)$ are shown in Figures 1 and 2. The thickness of all samples was within the limit as defined by the ASTM standard. The tensile testing was performed on an MTS- 810 machine at a strain rate of $2 \mathrm{~mm} / \mathrm{min}$. The sample during tensile testing is shown in Figure 3. A comparison of the different specimens tested on-axis and off-axis is demonstrated in Figures 4 and 5.

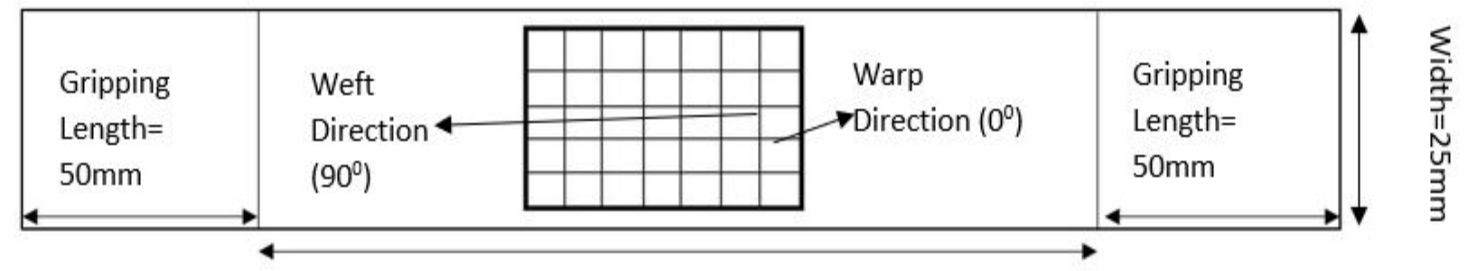

\section{Span Length $=150 \mathrm{~mm}$}

Figure 1. Tensile specimen for on-axis loading $\left(0^{\circ} / 90^{\circ}\right)$. 


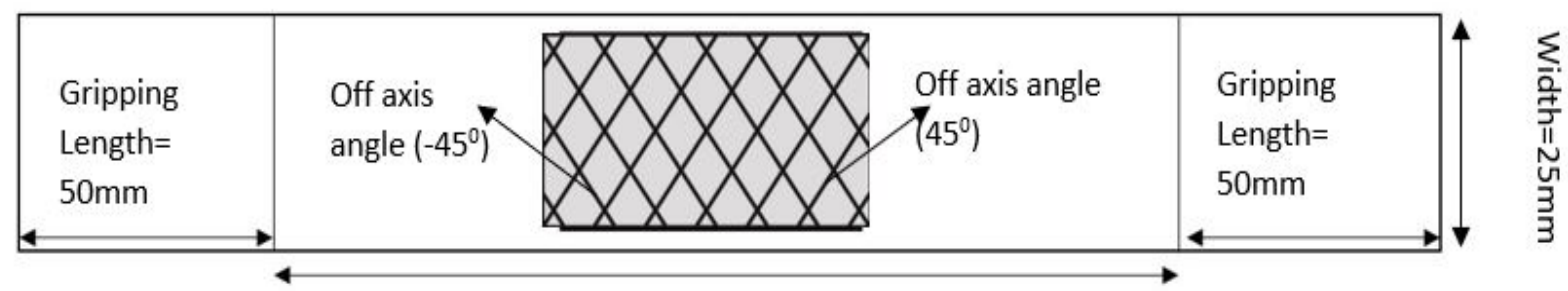

Span Length $=150 \mathrm{~mm}$

Figure 2. Tensile specimen for off-axis loading $\left( \pm 45^{\circ}\right)$.

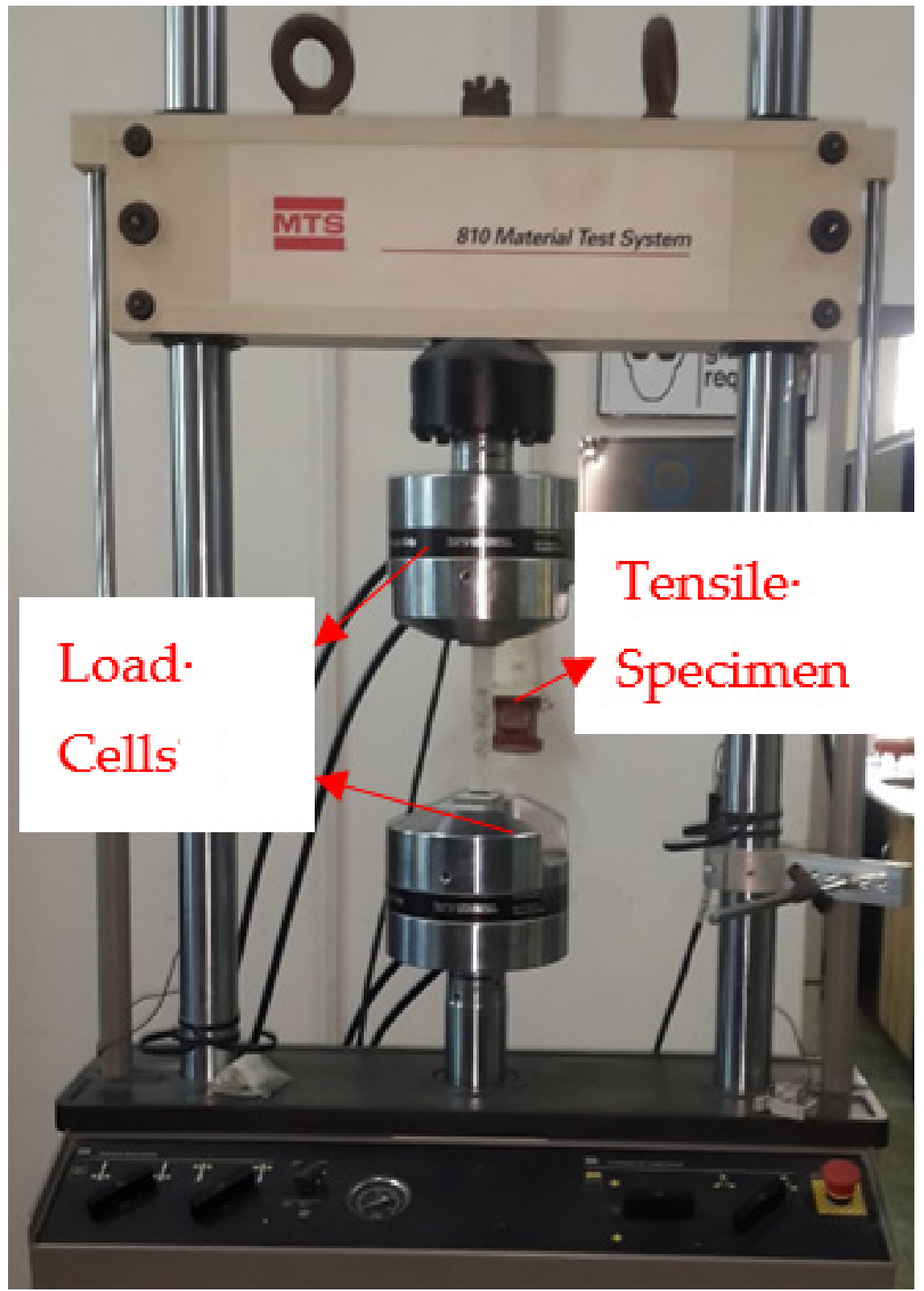

Figure 3. Tensile specimen during testing. 


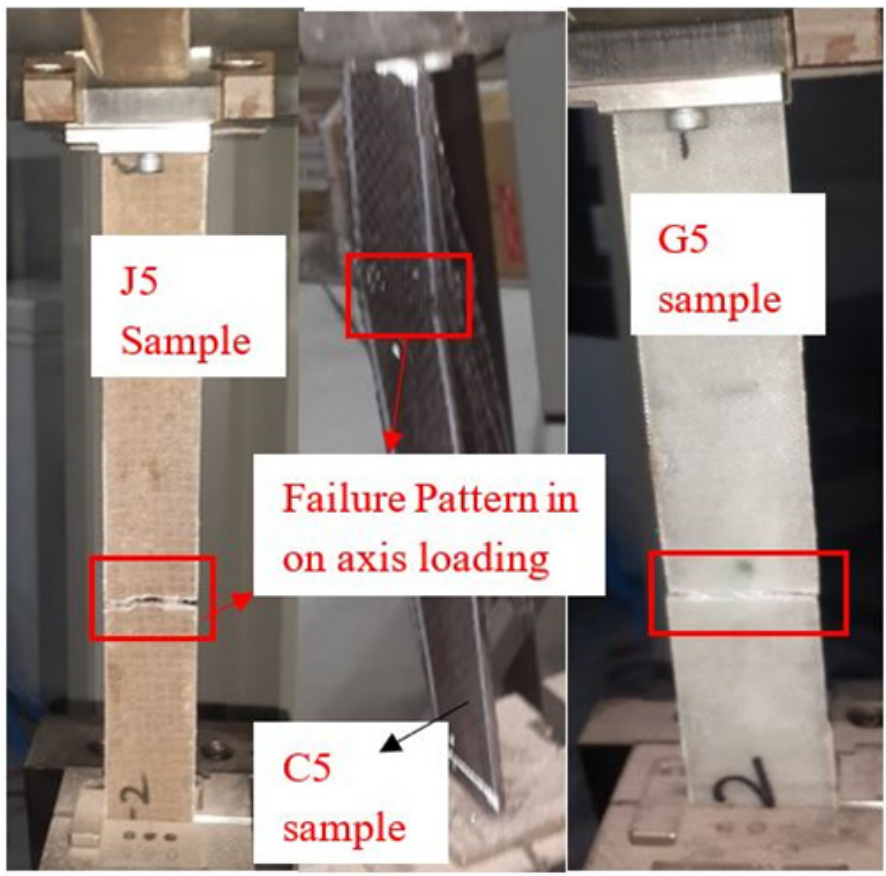

Figure 4. Tensile specimen during on-axis loading.

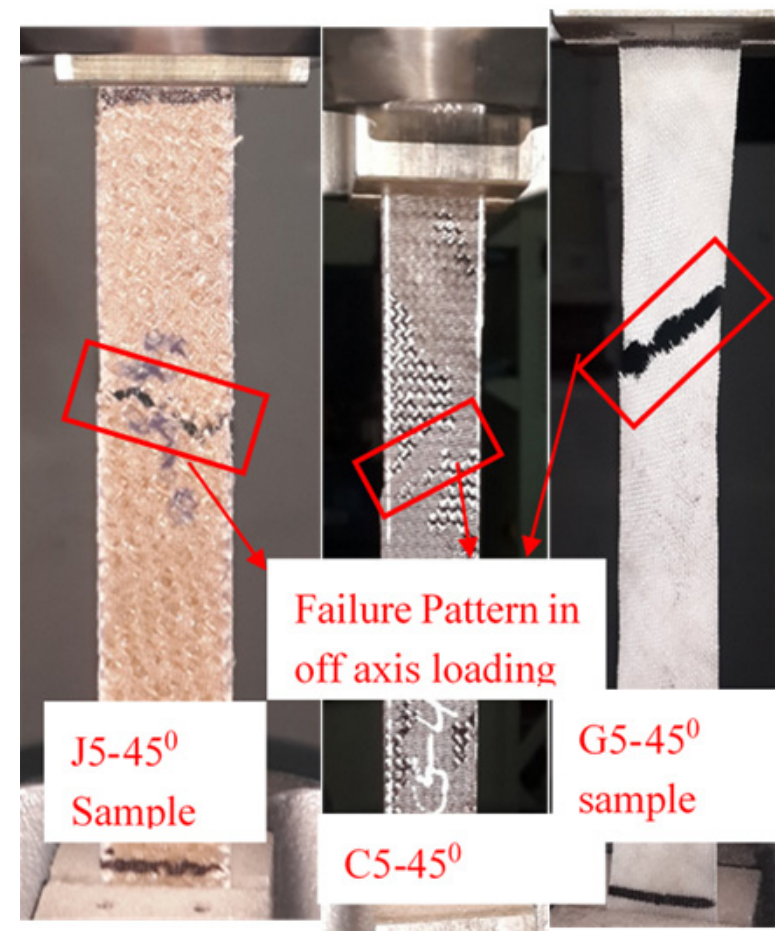

Figure 5. Tensile specimen during off-axis loading.

\section{Results and Discussions}

\subsection{On-Axis Loading}

The experiments were performed on carbon/epoxy, glass/epoxy, and jute/epoxy composites under both on-axis and off-axis loading according to ASTM D3039 standard. The mechanical properties of the above-tested composites are reported in Table 3. The carbon fiber-reinforced composite revealed the highest Young's modulus and tensile strength for on-axis loading among the materials tested, i.e., 17,407 $\mathrm{MPa}$ and $406 \mathrm{MPa}$, followed by glass-epoxy composites, having $8507 \mathrm{MPa}$ and $105 \mathrm{MPa}$ Young's modulus and tensile 
strength, respectively. Lastly, jute fiber-reinforced composite had a Young's modulus and tensile strength of $5107 \mathrm{MPa}$ and $49 \mathrm{MPa}$, respectively. The carbon-reinforced composite's higher mechanical properties are due to the fiber's stiffer nature and very high strength than glass and jute fiber [31]. The lower Young's modulus and tensile strength of jute fiber were due to inferior mechanical properties and since it was not hybridized with any synthetic fiber [32,33]. Figure 6 presents the stress vs. strain response under the tensile test of all stacking sequences. These diagrams clearly illustrate the brittle behavior of composites under on-axis loading. The brittle nature of these composite is the leading cause of lower failure strain.

Table 3. Engineering data from on-axis loading with a standard deviation.

\begin{tabular}{ccccc}
\hline Layup Sequence & $\begin{array}{c}\text { Thickness }(\mathbf{t}) \\
(\mathbf{m m})\end{array}$ & $\begin{array}{c}\text { Young's Modulus (E) } \\
\mathbf{( M P a )}\end{array}$ & $\begin{array}{c}\text { Tensile Strength }\left(\sigma_{\boldsymbol{u}}\right) \\
\mathbf{( M P a )}\end{array}$ & $\begin{array}{c}\text { Maximum Failure Strain }\left(\varepsilon_{\boldsymbol{u}}\right) \\
\mathbf{( \% )}\end{array}$ \\
\hline G5 & 1.3 & $8507 \pm 108$ & $105 \pm 5.87$ & $1.75 \pm 0.1$ \\
C5 & 1.4 & $17407 \pm 341$ & $406 \pm 13.05$ & $3.75 \pm 0.1$ \\
J5 & 2.9 & $5107 \pm 149$ & $49 \pm 1.08$ & $1.3 \pm 0.6$ \\
\hline
\end{tabular}

\subsection{Off-Axis Loading}

The mechanical properties under the off-axis loading of these composites are presented in Table 4. Under off-axis loading, carbon and glass fiber-reinforced composites revealed the same Young's modulus, i.e., $4068 \mathrm{MPa}$ and $4125 \mathrm{MPa}$, respectively. However, there was a $56 \%$ loss in tensile strength and $90 \%$ gain in failure strain for glass fiber composites in off-axis loading. More stretching of glass fiber in off-axis loading explains the ductility imparted in glass fiber composites in off-axis loading. Similarly, loss in tensile strength for carbon fiber composite was 77\%, and failure strain gain was $70 \%$. For jute fiber composites, the failure strain improved by $85 \%$ ( $2.72 \%$ from $1.3 \%)$, too low for jute composite. The reasons for this ductile behavior [17] of these composites are the orientation of fiber strands at $45^{\circ}$ angles throughout the specimens, the flattening of the sample under off-axis loading, and the fiber's ability to show more elongation with poor load transfer between the clamping regions (Figure 5). The effect of changing from an on-axis mode to an off-axis is like flattening to a cylinder-shaped interwoven composite structure, which can result in complete extension (high failure strain of the gauge length). Therefore, in off-axis loading, the failure is mainly due to the breaking of the fibers [34].

Table 4. Engineering data from off-axis loading with a standard deviation.

\begin{tabular}{ccccc}
\hline Layup Sequence & $\begin{array}{c}\text { Thickness }(\mathbf{t}) \\
(\mathbf{m m})\end{array}$ & $\begin{array}{c}\text { Young's Modulus (E) } \\
\mathbf{( M P a )}\end{array}$ & $\begin{array}{c}\text { Tensile Strength }\left(\sigma_{\boldsymbol{u}}\right) \\
\mathbf{( M P a )}\end{array}$ & $\begin{array}{c}\text { Maximum Failure Strain }\left(\varepsilon_{\boldsymbol{u}}\right) \\
\mathbf{( \% )}\end{array}$ \\
\hline G5-45 & 1.3 & $4125 \pm 161.6$ & $58.8 \pm 3.14$ & $17.58 \pm 0.94$ \\
C5-45 & 1.4 & $4068 \pm 345.9$ & $75.13 \pm 2.66$ & $12.32 \pm 0.73$ \\
J5-45 & 2.9 & $803 \pm 15.27$ & $20.13 \pm 1.25$ & $2.72 \pm 0.13$ \\
\hline
\end{tabular}

Similar results were reported in the previous studies by different researchers, i.e., Gliesche et al. [35], Gowtham et al. [10], Yan et al. [16], and Zhang et al. [15]. These studies concluded that a higher failure strain was observed in glass fiber composites. In another study, an elastoplastic model was developed for composites under off-axis tensile loading. This model usefully predicted the non-linear behavior of composites under offaxis loading [36]. Figure 7 presents the stress vs. strain response under the tensile test of all stacking sequences. It is evident from stress vs. strain graphs that these composite materials followed similar behavior to the ductile stress vs. strain trends. The bar charts of tensile strength and failure strain for all tested composites at different loading are shown in Figures 8 and 9. 


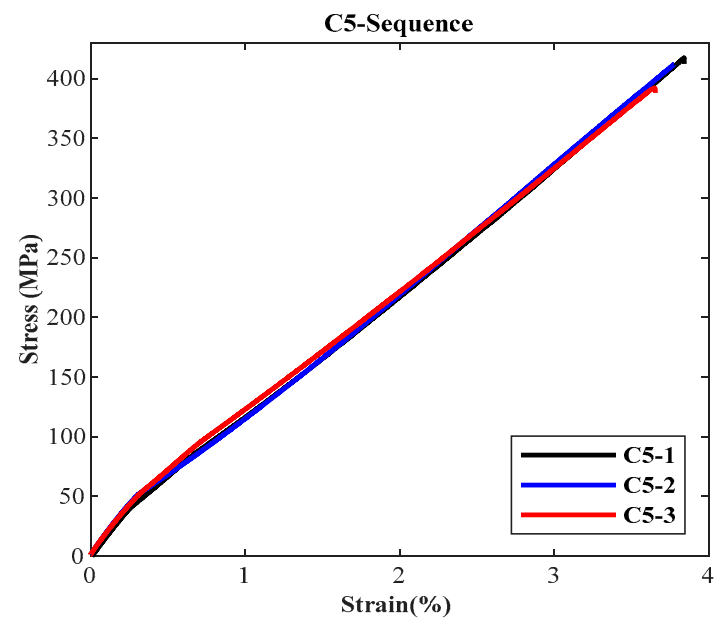

(a)

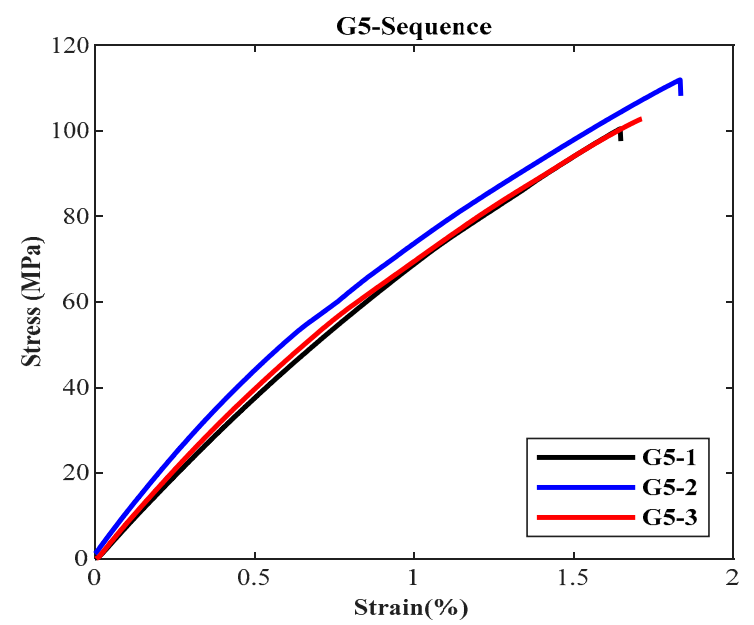

(b)

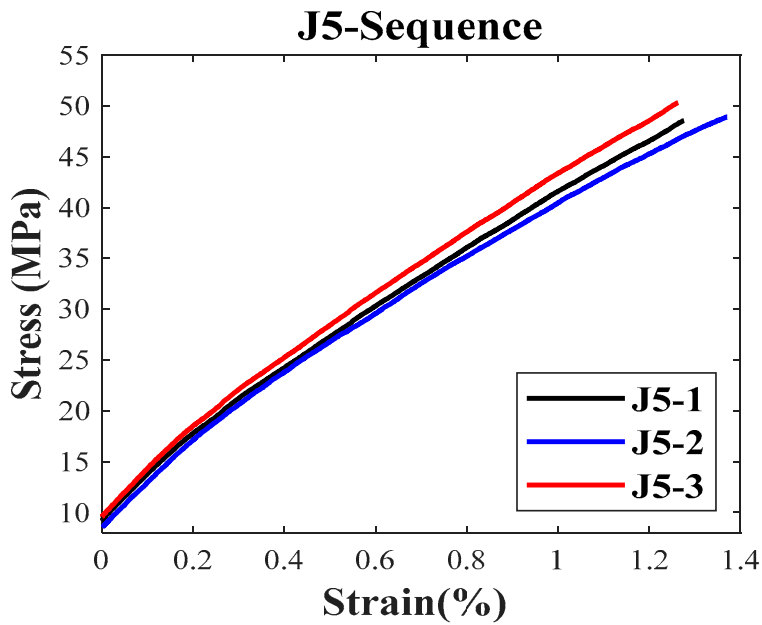

(c)

Figure 6. Comparison of stress vs. strain graphs of different samples at on-axis loading (a) C5 (b) G5 (c) J5. 


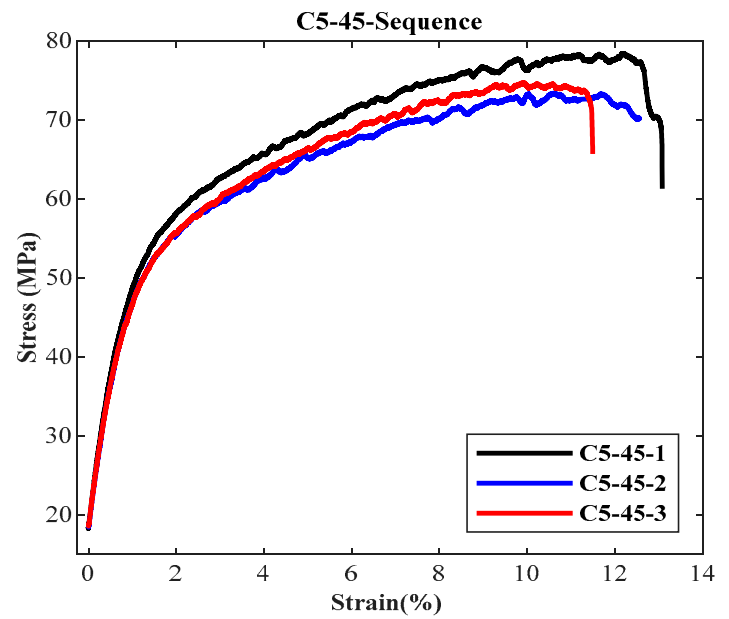

(a)

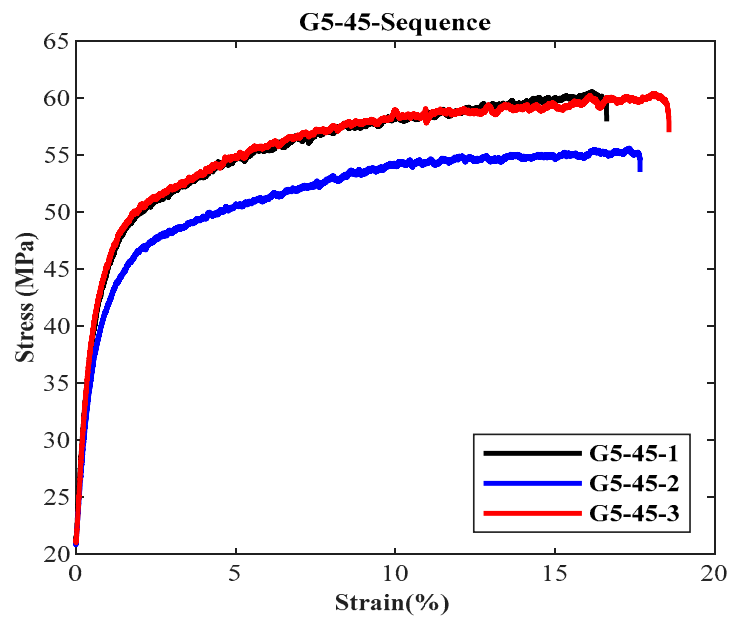

(b)

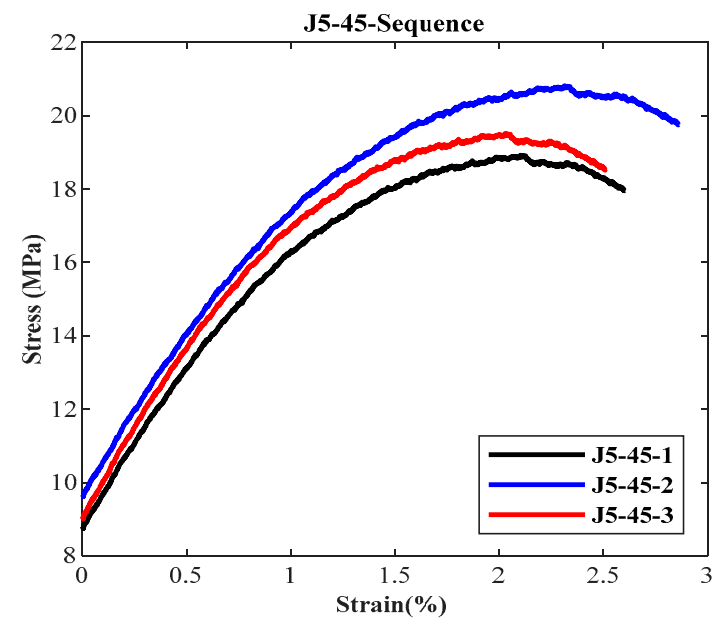

(c)

Figure 7. Comparison of stress vs. strain graphs of different samples at off-axis loading (a) C5-45 (b) G5-45 (c) J5-45. 


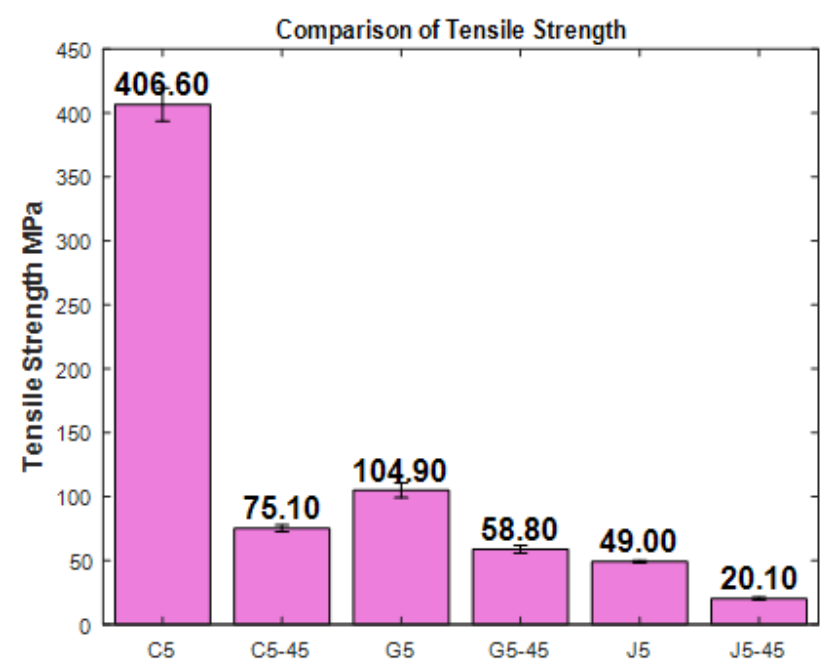

Figure 8. Comparison of tensile strength at different loading.

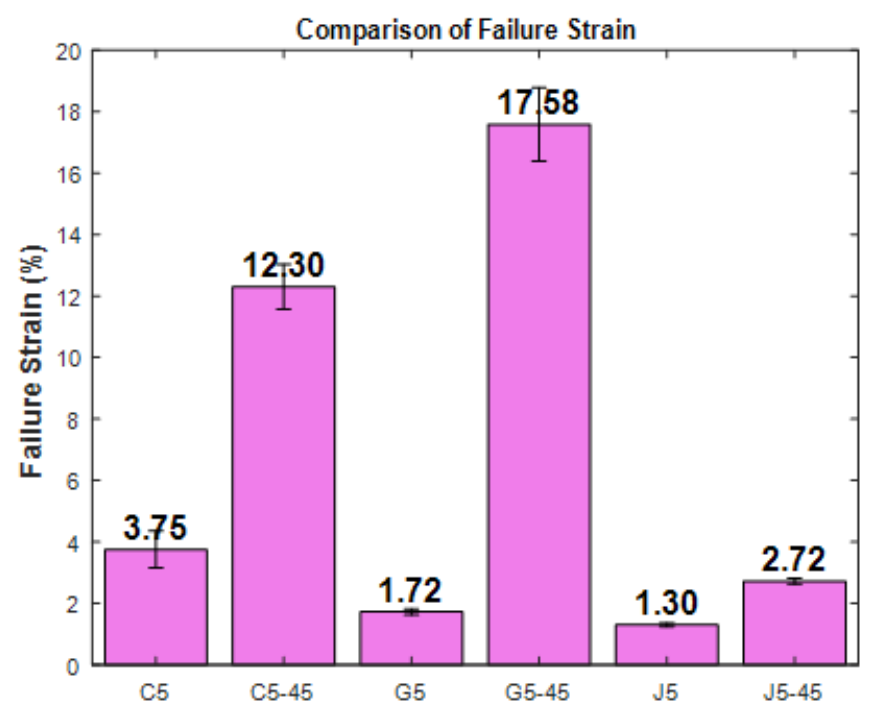

Figure 9. Comparison of failure strain at different loading.

\section{Conclusions and Future Perspective}

The fiber-reinforced composites' tensile failure behavior was studied under different loading conditions through an easy and reliable ASTM D3039 standard. The materials include carbon, E-glass, and jute fiber-reinforced composites. The study concludes that both on-axis and off-axis loading specimens can be prepared successfully through the hand layup technique. The tensile test results included stress vs. strain behavior and mechanical parameters, such as Young's modulus, tensile strength, and failure strain. It is concluded that:

(1) Under on-axis loading, epoxy/fiber composite show brittle behavior, whereas under off-axis loading, they show ductile behavior.

(2) Failure strain in on-axis loading ranged from $1.3 \%$ to $3.75 \%$, which is relatively low. This brittle behavior limits the applications of epoxy/fiber composites under on-axis loading conditions.

(3) In off-axis loading, glass/epoxy composites showed a good response with a $56 \%$ loss in tensile strength and $90 \%$ gain in failure strain. The failure strain ranged from $2.72 \%$ to $17.58 \%$ in off-axis loading for all composites.

(4) It is recommended that whenever ductility or failure strain in the composite is desired, use glass fiber as a single layer or in hybridization with any natural fiber reinforcement. 
(5) Jute/epoxy composite revealed inferior mechanical properties compared to carbon/epoxy and glass/epoxy in both on and off-axis loading. Therefore, it is recommended to use jute fiber only in hybridization with any synthetic fiber.

Future work from this study can be explored in many ways; for example, numerical simulation of these composites, particularly under off-axis loading, will quite be interesting. Similarly, applying different manufacturing and chemical treatment techniques to these fibers and composites should also be explored.

Author Contributions: Conceptualization, A.A.R.; methodology, Z.U.A., and M.Y.K., and N.A.; software, H.A., and Z.U.A.; formal analysis, M.Y.K., H.A., and N.A.; investigation, M.Y.K., A.A.R., Z.U.A., and H.A.; writing—original draft preparation, M.Y.K.; writing—review and editing, A.A.R., M.Y.K., and H.A.; supervision, F.P.G.M.; project administration, F.P.G.M.; funding acquisition, F.P.G.M. All authors have read and agreed to the published version of the manuscript.

Funding: The work reported herewith has been financially by the Dirección General de Universidades, Investigación e Innovación of Castilla-La Mancha, under Research Grant ProSeaWind project (Ref.: SBPLY/19/180501/000102).

Data Availability Statement: Experimental data will be available on request.

Conflicts of Interest: The authors declare no conflict of interest.

\section{References}

1. Al Rashid, A.; Khan, S.A.; Al-Ghamdi, S.G.; Koç, M. Additive manufacturing: Technology, applications, markets, and opportunities for the built environment. Autom. Constr. 2020, 118, 103268. [CrossRef]

2. Rashid, A.A.; Khan, S.A.; Al-Ghamdi, S.G. Critical Review on 3DP Concrete trends, needs and research recommendation. In International Conference of Materials and Engineering Technology (TICMET'20); Gaziantep, Turkeys, 5-7 November 2020.

3. Al-Rashid, M.A.; Nahiduzzaman, K.M.; Ahmed, S.; Campisi, T.; Akgün, N. Gender-Responsive Public Transportation in the Dammam Metropolitan Region, Saudi Arabia. Sustainability 2020, 12, 9068. [CrossRef]

4. Al-Rashid, M.A.; Goh, H.C.; Harumain, Y.A.S.; Ali, Z.; Campisi, T.; Mahmood, T. Psychosocial Barriers of Public Transport Use and Social Exclusion among Older Adults: Empirical Evidence from Lahore, Pakistan. Int. J. Environ. Res. Public Heal. 2020, 18, 185. [CrossRef]

5. Heimbs, S.; Schmeer, S.; Middendorf, P.; Maier, M. Strain rate effects in phenolic composites and phenolic-impregnated honeycomb structures. Compos. Sci. Technol. 2007, 67, 2827-2837. [CrossRef]

6. Khalid, M.; Al Rashid, A.; Sheikh, M. Effect of Anodizing Process on Inter Laminar Shear Strength of GLARE Composite through T-Peel Test: Experimental and Numerical Approach. Exp. Tech. 2021, 1-9. [CrossRef]

7. Winkelmann, C.; Kim, S.S.; La Saponara, V. Design and development of hybrid composite bistable structures for energy absorption under quasi-static tensile loading. Compos. Struct. 2010, 93, 171-178. [CrossRef]

8. Shah, D.U.; Schubel, P.J.; Clifford, M.J.; Licence, P. The tensile behavior of off-axis loaded plant fiber composites: An insight on the nonlinear stress-strain response. Polym. Compos. 2012, 33, 1494-1504. [CrossRef]

9. Al Rashid, A.; Imran, R.; Khalid, M.Y. Determination of opening stresses for railway steel under low cycle fatigue using digital image correlation. Theor. Appl. Fract. Mech. 2020, 108, 102601. [CrossRef]

10. Gowtham, H.; Pothnis, J.R.; Ravikumar, G.; Naik, N. High strain rate in-plane shear behavior of composites. Polym. Test. 2013, 32, 1334-1341. [CrossRef]

11. Callens, M.; Gorbatikh, L.; Verpoest, I. Ductile steel fibre composites with brittle and ductile matrices. Compos. Part. A: Appl. Sci. Manuf. 2014, 61, 235-244. [CrossRef]

12. Schmeer, S.; Steeg, M.; Maier, M.; Mitschang, P. Metal Fibre Reinforced Composite-Potentialities and Tasks. Adv. Compos. Lett. 2009, 18, 1-8. [CrossRef]

13. Foroutan, R.; Nemes, J.; Ghiasi, H.; Hubert, P. Experimental investigation of high strain-rate behaviour of fabric composites. Compos. Struct. 2013, 106, 264-269. [CrossRef]

14. J Gassan, J.; Bledzki, A.K. Possibilities to improve the properties of natural fiber reinforced plastics by fiber modification-Jute polypropylene composites. Appl. Compos. Mater. 2000, 7, 373-385. [CrossRef]

15. Zhang, L.; Liu, W.; Wang, L.; Ling, Z. On-axis and off-axis compressive behavior of pultruded GFRP composites at elevated temperatures. Compos. Struct. 2020, 236, 111891. [CrossRef]

16. Ma, Y.; Zhang, Y.; Sugahara, T.; Jin, S.; Yang, Y.; Hamada, H. Off-axis tensile fatigue assessment based on residual strength for the unidirectional $45^{\circ}$ carbon fiber-reinforced composite at room temperature. Compos. Part. A Appl. Sci. Manuf. 2016, 90, 711-723. [CrossRef]

17. Pandita, S.D.; Huysmans, G.; Wevers, M.; Verpoest, I. Tensile fatigue behaviour of glass plain-weave fabric composites in on- and off-axis directions. Compos. Part. A: Appl. Sci. Manuf. 2001, 32, 1533-1539. [CrossRef] 
18. Soliman, E.; Kandil, U.; Taha, M.R. Improved Strength and Toughness of Carbon Woven Fabric Composites with Functionalized MWCNTs. Materials 2014, 7, 4640. [CrossRef]

19. Cao, Y.; Cai, Y.; Zhao, Z.; Liu, P.; Han, L.; Zhang, C. Predicting the tensile and compressive failure behavior of angle-ply spread tow woven composites. Compos. Struct. 2020, 234, 111701. [CrossRef]

20. Kalteremidou, K.-A.; Hajikazemi, M.; Van Paepegem, W.; Van Hemelrijck, D.; Pyl, L. Effect of multiaxiality, stacking sequence and number of off-axis layers on the mechanical response and damage sequence of carbon/epoxy composite laminates under static loading. Compos. Sci. Technol. 2020, 190, 108044. [CrossRef]

21. Bergmann, T.; Heimbs, S.; Maier, M. Mechanical properties and energy absorption capability of woven fabric composites under $\pm 45^{\circ}$ off-axis tension. Compos. Struct. 2015, 125, 362-373. [CrossRef]

22. Aruchamy, K.; Subramani, S.P.; Palaniappan, S.K.; Sethuraman, B.; Kaliyannan, G.V. Study on mechanical characteristics of woven cotton/bamboo hybrid reinforced composite laminates. J. Mater. Res. Technol. 2020, 9, 718-726. [CrossRef]

23. Rabiee, A.; Ghasemnejad, H. Laminate Tailoring of Composite Tubular Structures to Improve Crashworthiness Design at Off-Axis Loading. Open J. Compos. Mater. 2018, 8, 84-109. [CrossRef]

24. Al Rashid, A.; Khalid, M.Y.; Imran, R.; Ali, U.; Koc, M. Utilization of Banana Fiber-Reinforced Hybrid Composites in the Sports Industry. Materials 2020, 13, 3167. [CrossRef] [PubMed]

25. Khalid, M.Y.; Nasir, M.A.; Ali, A.; Al Rashid, A.; Khan, M.R. Experimental and numerical characterization of tensile property of jute/carbon fabric reinforced epoxy hybrid composites. Sn Appl. Sci. 2020, 2. [CrossRef]

26. Ali, A.; Nasir, M.A.; Khalid, M.Y.; Nauman, S.; Shaker, K.; Khushnood, S.; Altaf, K.; Zeeshan, M.; Hussain, A. Experimental and numerical characterization of mechanical properties of carbon/jute fabric reinforced epoxy hybrid composites. J. Mech. Sci. Technol. 2019, 33, 4217-4226. [CrossRef]

27. Landis, C.M.; Beyerlein, I.J.; Mcmeeking, R.M. Micromechanical simulation of the failure of fiber reinforced composites. J. Mech. Phys. Solids 2000, 48, 621-648. [CrossRef]

28. Rouison, D.; Sain, M.; Couturier, M. Resin transfer molding of natural fiber reinforced composites: Cure simulation. Compos. Sci. Technol. 2004, 64, 629-644. [CrossRef]

29. Kolpakov, A.; Rakin, S. Homogenized strength criterion for composite reinforced with orthogonal systems of fibers. Mech. Mater. 2020, 148, 103489. [CrossRef]

30. Zahid, S.; Nasir, M.A.; Nauman, S.; Karahan, M.; Nawab, Y.; Ali, H.M.; Khalid, Y.; Nabeel, M.; Ullah, M. Experimental analysis of ILSS of glass fibre reinforced thermoplastic and thermoset textile composites enhanced with multiwalled carbon nanotubes. $J$. Mech. Sci. Technol. 2019, 33, 197-204. [CrossRef]

31. Fu, S.Y.; Lauke, B.; M\&\#xE4, E.; der, E.; Yue, C.Y.; Hu, X.; Mai, Y.W. Hybrid effects on tensile properties of hybrid short-glass-fiberand short-carbon-fiber-reinforced polypropylene composites. J. Mater. Sci. 2001, 1243-1251. [CrossRef]

32. Ramesh, M.; Palanikumar, K.; Reddy, K.H. Comparative Evaluation on Properties of Hybrid Glass Fiber- Sisal/Jute Reinforced Epoxy Composites. Procedia Eng. 2013, 51, 745-750. [CrossRef]

33. Sezgin, H.; Berkalp, O.B. The effect of hybridization on significant characteristics of jute/glass and jute/carbon-reinforced composites. J. Ind. Text. 2017, 47, 283-296. [CrossRef]

34. Gowda, T.M.; Naidu, A.; Chhaya, R. Some mechanical properties of untreated jute fabric-reinforced polyester composites. Compos. Part. A Appl. Sci. Manuf. 1999, 30, 277-284. [CrossRef]

35. Gliesche, K.; Hübner, T.; Orawetz, H. Investigations of in-plane shear properties of $\pm 45^{\circ}$-carbon/epoxy composites using tensile testing and optical deformation analysis. Compos. Sci. Technol. 2005, 65, 163-171. [CrossRef]

36. Wang, H.; Duan, Y.; Abulizi, D.; Zhang, X. Design optimization of CFRP stacking sequence using a multi-island genetic algorithms under low-velocity impact loads. J. Wuhan Univ. Technol. Sci. Ed. 2017, 32, 720-725. [CrossRef] 